\title{
Mindfulness mediates the relationship between cognitive reappraisal and resilience in higher education students
}

Nicolò Zarottia, Claire Povahb ${ }^{b}$ Jane Simpsona1

a Division of Health Research, Faculty of Health and Medicine, Lancaster University, Lancaster, UK

b Student Based Services, Lancaster University, Lancaster, UK

${ }^{1}$ Corresponding author. Tel.: +44 01524 592858. E-mail: j.simpson2@lancaster.ac.uk. Address: Division of Health Research, Faculty of Health and Medicine, Lancaster University, LA1 4YG, Lancaster, UK. 


\section{Abstract}

Background: associations between the constructs of cognitive reappraisal and resilience, in particular within the context of higher education (HE), have been consistently reported. Moreover, both constructs are strongly and positively associated with mindfulness, meaning that higher levels of mindfulness are found in people who are better at reappraising emotions and being resilient. However, no investigation has so far clarified the role that may mindfulness play in the relationship between cognitive reappraisal and resilience, especially within populations where a strong effect, such as for university students, is already evident.

Aims: the present study tested the hypothesis that mindfulness plays a mediational role in the association between cognitive reappraisal and psychological resilience.

Sample: this study involved a sample of 811 students enrolled at universities within the UK.

Results: the data confirmed the strong relationship between cognitive reappraisal and resilience, as well as each construct's individual association with mindfulness. In addition, mindfulness was a significant mediator of the relationship between cognitive appraisal and resilience, thus corroborating the study's main hypothesis.

Conclusions: as the concern around students' mental health grows bigger worldwide, these findings suggest that implementing mindfulness training programmes within HE should be given increasing consideration in the future.

\section{Keywords}

Mindfulness; emotion regulation; cognitive reappraisal; resilience; university students, higher education. 


\section{Introduction}

Emotion regulation is defined as the process of determining which emotions are felt, as well as when and how they are experienced or expressed (Gross, 1998). Its importance for mental health has been widely recognised over the last three decades (e.g., Eftekhari, Zoellner, \& Vigil, 2009). Among the many emotion regulation strategies is cognitive reappraisal, which involves the active rethinking of an event or a situation to alter the connected emotional response (Gross, 2015). When cognitive reappraisal results in a more adaptive emotion, this has been shown to be linked positively to psychological resilience (Troy \& Mauss, 2011), the ability to 'bounce back' against trauma or adversities and return to an adaptive level of psychological functioning (Smith et al., 2008). Evidence of this relationship - cognitive reappraisal leading to higher levels of resilience - has been found in a variety of populations and settings, including employees in work environments (Kay, 2016), extremely arousing situations (e.g., skydiving; Carlson, Dikecligil, Greenberg, \& Mujica-Parodi, 2012), as well as undergraduate students in higher education institutions (Shiota, 2006).

Some of the processes involved in cognitive reappraisal also show important similarities with the cognitive processes outlined in theoretical accounts of mindfulness, which has been defined as a quality of consciousness consisting of being receptively attentive to and aware of events and experiences of the present moment (Brown \& Ryan, 2003). Both cognitive reappraisal and mindfulness may also involve similar neural circuits (i.e., medial prefrontal cortex and amygdala; Opialla et al., 2014) and be equally effective in regulating mood (Keng, Robins, Smoski, Dagenbach, \& Leary, 2013). Consistently, the studies investigating the connections between mindfulness and emotion regulation in general have reported that higher levels of mindfulness are positively correlated to healthier emotional regulatory habits, whereas low levels of mindfulness are associated with substantial emotional dysregulation in both healthy and clinical populations (Erisman \& Roemer, 2010; Feldman, Hayes, Kumar, Greeson, \& 
Laurenceau, 2007; Prakash, Whitmoyer, Aldao, \& Schirda, 2015; Vujanovic, Bonn-Miller, Bernstein, McKee, \& Zvolensky, 2010). This positive relationship appears to be even stronger in populations of young adults (Prakash et al., 2015; Vujanovic et al., 2010).

In addition to emotion regulation, the construct of mindfulness has also been shown to share a significant relationship with resilience, and psychological adjustment after exposure to trauma in particular (Thompson, Arnkoff, \& Glass, 2011). Moreover, the increase in the adoption of mindfulness-based psychological interventions (MBIs) has evidenced the trigger of many beneficial effects (Allen, Blashki, \& Gullone, 2006), including higher levels of resilience (Baer, 2003). Again, this appears to be even more relevant to young adults in the higher education setting, as resilience has been often indicated as important for a successful adjustment to university life (Pooley \& Cohen, 2010), self-efficacy (Cassidy, 2015), and academic success (Waxman, Gray, \& Padron, 2003), and several studies focused on students reported a significant relationship between mindfulness traits, mental health, psychological well-being, and resilience (Galante et al., 2018; Hindman, Glass, Arnkoff, \& Maron, 2014; Palmer \& Rodger, 2009; Pidgeon \& Keye, 2014; Regehr, Glancy, \& Pitts, 2013; Rogers, 2013; Van Gordon, Shonin, Sumich, Sundin, \& Griffiths, 2014).

Interestingly, some of the most recent evidence on emotion regulation interventions in university students has shown that mindfulness-based regulation strategies are more strongly associated with decreased negative affect compared to cognitive reappraisal (Brockman, Ciarrochi, Parker, \& Kashdan, 2017), and that a combined 'mindful positive reappraisal' approach yields significantly lower negative affect scores compared to reappraisal alone (Pogrebtsova, Craig, Chris, O’Shea, \& González-Morales, 2018).

Together, these findings appear to suggest that cognitive appraisal has its relationship on resilience through greater levels of mindfulness. However, to date no investigation has addressed the hypothesis that mindfulness plays a role in mediating the expression of the 
relationship between cognitive reappraisal and resilience - especially in populations for which the literature suggests a more relevant effect, such as people enrolled in higher education. Thus, the overarching aim of the present study was to test the hypothesis that mindfulness mediates the relationship between cognitive reappraisal and psychological resilience in university students.

\section{Method}

\section{Participants}

A sample of 811 students enrolled at universities in the United Kingdom took part in the present study. The inclusion criteria were: aged 18 or more, currently enrolled onto a university degree course, and a native English speaker or having a fluent command of English. Both undergraduate and postgraduate students were included (53.9\% and 46.1\% respectively), across main five subject categories (Arts and Humanities, Engineering and Technology, Life Sciences and Medicine, Natural Sciences, and Social Sciences and Management). Postgraduate students were included due to evidence suggesting that the adjustment to postgraduate education in the UK can be rather challenging, in particular for international individuals (Brown \& Holloway, 2008; Wu \& Hammond, 2011; Young, Sercombe, Sachdev, Naeb, \& Schartner, 2013).

\section{Power analysis}

Based on the power tables for mediation analysis (Fritz \& Mackinnon, 2015), assuming a medium effect size (.39) for the mediated effect $(\alpha \beta)$, a minimum sample of 71 participants was required to achieve a minimum statistical power of .80. As a consequence, the sample size was more than sufficient and suggests statistical power of over 95\%. Table 1 illustrates the demographic characteristics of the sample. 
[Table 1 near here]

\section{Measures}

Emotion Regulation Questionnaire (ERQ; Gross \& John, 2003).

The ERQ is a validated self-report questionnaire based on 10 items rated on a 7-point Likert scale. It evaluates the respondent's tendency to adopt two specific emotion regulation strategies: Cognitive Reappraisal and Expressive Suppression. A separate score is produced for each strategy at the end of the questionnaire. The ERQ has shown both good internal consistency (Cronbach's $\alpha=.71 / .79$ ) and test-retest validity (i.e., .69; Enebrink, Björnsdotter, \& Ghaderi, 2013). For the purpose of this study, the cognitive reappraisal score (ERQ-C), which ranges from 6 to 42, was adopted for the analysis. Higher scores on the ERQ-C correspond to higher cognitive reappraisal skills.

Brief Resilience Scale (BRS; Smith et al., 2008).

The BRS is a self-report questionnaire consisting of 6 items rating resilience on a 5-point Likert scale. It yields a total score ranging from 6 to 30, with higher scores meaning higher levels of resilience. The BRS has been validated in adult populations in several languages, and features high internal consistency (Cronbach's $\alpha=.83$ ) and test-retest validity (i.e., .69; Chmitorz et al. 2018; Rodríguez-Rey et al. 2016).

Five Facets of Mindfulness Questionnaire (FFMQ; Baer, Smith, Hopkins, \& Toney, 2006). 
The FFMQ is one of the most adopted validated self-report questionnaires to measure mindfulness. It consists of 39 items rated on a 5-point Likert scale, comprising five subscales: observing, describing, acting with awareness, non-judging of inner experience, and nonreactivity to inner experience. All the subscales can be combined to yield a total score ranging from 39 to 195, which was adopted for the purpose of the present study. Higher scores indicate higher levels of mindfulness. The FFMQ has consistently shown excellent psychometric properties (Baer, Walsh, \& Lykins, 2009), with high levels of construct validity (Montgomery, Hatton, Fisk, Ogden, \& Jansari, 2010) as well as reliability, with Cronbach alphas for the subscales in the range of 0.73-0.91 (Sung-Youl, 2015). It is suitable for online administration (Veehof, Ten Klooster, Taal, Westerhof, \& Bohlmeijer, 2011), has been adopted both in the UK and internationally with numerous samples consisting of university students (de Bruin, Topper, Muskens, Bögels, \& Kamphuis, 2012; Schmidt \& Vinet, 2016; Sugiura, Sato, Ito, \& Murakami, 2012; Tran, Glück, \& Nader, 2013).

\section{Procedure}

All data were collected via a web-based survey designed with the Qualtrics® software. This was adopted to allow for the opportunity to target a large population of students, as well due to considerable ethical advantages, including the guarantee of anonymity and lower likelihood of answers driven by social desirability. The link to the study was disseminated via the researchers' host university website and social media. Informed consent was obtained at the start of the survey, and it was made clear to the participants that they could withdraw from the study at any time by closing their browser without having their response registered. The research design was approved by the first author's host institution Research Ethics Committee (Ref: FHMREC16084)

\section{Data Analysis}


Data were analysed with the Statistical Package for the Social Sciences (SPSS) Version 26. The mediation analyses were performed as outlined by Hayes (2018) to examine whether the total level of mindfulness mediated the relationship between cognitive reappraisal and resilience. Traditionally, four criteria have been proposed to justify the testing of a mediation analysis (Baron \& Kenny, 1986): 1) the predictor variable $(X)$ must significantly predict the outcome variable $(Y)$ - this is known as the $c$ path; 2) the predictor variable $(X)$ must significantly predict the mediator $(M)$ - the $a$ path; 3) the mediator $(M)$ must significantly predict the outcome variable $(Y)$ - the $b$ path; and lastly, 4) the predictor variable $(X)$ must predict the outcome variable $(Y)$ less strongly when the mediator $(M)$ is added to the model the $c^{\prime}$ 'path or 'indirect effect'. Accordingly, mediation is suggested if the relationship between the predictor $(X)$ and the outcome variable $(Y)$ is significantly reduced when the mediator $(M)$ is introduced in the model ( $c-c^{\prime}$ path). When tested for assumptions of normality (Shapiro-Wilk test), all three variables in the present study were non-normal at $p<$ .05. Consequently, a non-parametric correlational analysis was performed using Spearman's $r_{s}$ (two-tailed) in order to test the relationship between cognitive reappraisal (ERQ-CR), resilience (BRS), and mindfulness (FFMQ). Correlations were estimated to be small at $r_{s}=.10$, medium at $r_{s}=.30$, and large at $r_{s}=.50$ and above (Watson, 2016).

However, Hayes (2018) recently argued whether meeting all four conditions is in fact required for mediation to occur, while focusing more on whether the mediator $(M)$ can causally be located between the predictor $(X)$ and the outcome variable $(Y)$. Thus, while the traditional criteria were checked as to whether the testing of a mediation effect was justified, the PROCESS macro for SPSS version 3.4 developed by Hayes (2018) was adopted for the mediation analysis in the present study. In particular, taking into account the non-normal distribution of the data, a bias-corrected confidence interval (95\%) based on 5000 bootstrap replications was used to determine the significance of the indirect effect ( $c^{\prime}$ path). 


\section{Results}

\section{Measures}

The descriptive data for the scales adopted in the present study are reported in Table 2, along with measures of internal consistency (Cronbach's alpha). On average, the sample scored 28.09/42 on cognitive reappraisal, $18.59 / 30$ on resilience, and 122.3/140 on mindfulness. All the scales included in the present mediation analysis demonstrated excellent to very good internal consistency (ERQ-CR, $\alpha=.805$; BRS, $\alpha=.893$; FFMQ, $\alpha=.762$ ).

[Table 2 near here]

\section{Correlational Analysis}

The results from Spearman's $r_{s}$ correlational analyses confirmed that the predictor (cognitive reappraisal, ERQ-CR), mediator (mindfulness, FFMQ), and outcome variable (resilience, BRS) all shared significant positive large associations with one another. In particular, increased cognitive appraisal significantly correlated with increased resilience $\left(r_{s}=.45, p<.001\right)$, and increased mindfulness $\left(r_{s}=.50, p<.001\right)$. Similarly, higher levels of mindfulness significantly correlated with higher levels of resilience $\left(r_{s}=.61, p<.001\right)$. Table 3 illustrates the results of the correlational analysis.

[Table 3 near here]

\section{Mediation Analysis}


In the mediation model regression pathways showed that increased cognitive reappraisal (ERQ-CR) was a significant predictor of higher levels of resilience (BRS; the $c$ pathway: $b=.332$ ,$p<.001$ ). Increased ERQ-CR also predicted increased mindfulness (FFMQ; the $a$ pathway: $b=$ $-.1492, p<.001$ ). Similarly, higher levels of FFMQ predicted increased BRS (the $b$ pathway: $b=$ $.126, p<.001)$. Finally, the relationship between ERQ and BRS was decreased with FFMQ as an adjustor (the $c^{\prime}$ pathway: $b=.143, p<.001$ ). The observed indirect effect indicated that mediation had occurred from ERQ-C to BRS through FFMQ, $a b=0.188,95 \%$ BCa CI [0.157, 0.222], and the completely standardised effect size reflected the same result, $a b_{c s}=0.258, \mathrm{BCa}$ CI $[0.218,0.302]$. Figure 1 illustrates the path diagram of the model based on the whole sample.

[Figure 1 near here]

\section{Discussion}

This investigation adopted an online survey to test the hypothesis that mindfulness mediates the relationship between cognitive reappraisal and psychological resilience.

The mediation analysis showed that mindfulness significantly mediated the relationship between cognitive reappraisal and resilience. This finding corroborated our hypothesis, meaning that participants' level of mindfulness at least partially explained the association between their reappraisal skills and their ability to "bounce back" against adversities. This carries a number of both theoretical and practical implications.

From a theoretical perspective, the present findings add further corroboration to the notion that shifting cognitive sets by adopting a distanced view on one's internal and external experiences could represent a fundamental bridging concept between the constructs of 
mindfulness and cognitive reappraisal (Carmody, Baer, Lykins, \& Olendzki, 2009; HayesSkelton \& Graham, 2013). Moreover, they support the evidence suggesting that individuals with higher self-reported levels of mindfulness may be also show more psychologically resilient (Garland et al., 2011; Segal et al., 2002).

On the practical side, the observed mediation effect provides further support to the findings from several previous studies which tested the effectiveness of mindfulness-based psychological interventions with university students, and found that mindfulness training led to decreased levels of depression and anxiety, and ultimately better mental health and resilience (de Vibe et al., 2013; Galante et al., 2018; Lynch, Gander, Kohls, Kudielka, \& Walach, 2011; Oman, Shapiro, Thoresen, Plante, \& Flinders, 2008; Palmer \& Rodger, 2009; Regehr et al., 2013; Rogers, 2013). Moreover, since emotion regulation strategies currently represent a major focus of investigations on the mental health of university students (de Vibe et al., 2013; Monteiro, Balogun, \& Oratile, 2014; Monti \& Rudolph, 2014; Wang, Xu, Zhang, \& Fang, 2017; Webster \& Hadwin, 2015), our findings suggest and further support the notion that including mindfulness-based components in future interventions targeting emotion regulation with this population could lead to better outcomes (Brockman et al., 2017; Pogrebtsova et al., 2018). In particular, as concerning rates of depression, anxiety, and general mental health issues are being increasingly reported with university students (Auerbach et al., 2018; Regehr et al., 2013), this may prove a more effective way to improve students' psychological well-being, as well as tackle academic-specific issues such as lack of motivation, performance anxiety, and feelings of inadequacy.

\section{Limitations and future directions}

A number of important limitations should be considered along with the present results. First, the adoption of an online survey for this study carried the intrinsic limitation of lacking any 
form of direct contact between the researchers and the participants, which also means that the results are a product of self-reported measures. However, this was justified by the opportunity to enrol over 800 participants across multiple institutions and fields of study in the UK. Moreover, as pointed out in a recent state of the art review, "while the psychometric approach reveals weaknesses and unsolved problems, it remains the most used and most practicable approach for measuring mindfulness for the time being" (Sauer et al., 2013, p. 13).

Second, the fact that the present survey only included participants enrolled on higher education courses within the UK does not account for differences between education systems globally, which may have a potential impact on the expression of students' cognitive reappraisal strategies, mindfulness, and resilience skills, as well as their mental health in general. Therefore, the discussion and interpretation of the results in this study should be considered in combination with the specific context of British higher education institutions. Future investigations should also consider the inclusion of samples from multiple countries in order to allow for comparisons among different education systems.

Last, despite allowing for the in-depth exploration of the associations between mindfulness, cognitive reappraisal, and resilience in a large multicentre sample, the cross-sectional nature of this study does not allow to draw conclusions on the causal relationships between the observed constructs. However, this design offered a first look at the mindfulness-related mechanisms that may underlie the relationship between cognitive appraisal and resilience in students enrolled in higher education within the UK. In addition, it also builds support for the development of future longitudinal investigations aimed at verifying the robustness of the mediation effect of mindfulness over time, while at the same time shedding light on any potential causal implications.

\section{Conclusion}


This investigation indicated that mindfulness mediated the in relationship between cognitive reappraisal and psychological resilience in a sample of 811 university students across the UK. These findings suggest that mindfulness may represent an effective way to strengthen the relationship between cognitive reappraisal as well as resilience in university students, and ultimately provide a means to improve their academic performance and psychological wellbeing. As a high prevalence of mental health difficulties is increasingly reported within this population, the implementation of mindfulness support and training programmes within universities, both within the UK and internationally, should be given careful consideration for future studies.

\section{Conflict of interest}

The authors declare that they have no conflict of interest.

\section{References}

Allen, N. B., Blashki, G., \& Gullone, E. (2006). Mindfulness-based psychotherapies : a review of conceptual foundations, empirical evidence. Australian and New Zealand Journal of Psychiatry, (40), 285-294. https://doi.org/10.1111/j.1440-1614.2006.01794.x

Auerbach, R. P., Hasking, P., Kessler, R. C., Nock, M. K., Murray, E., Mortier, P., ... Green, J. G. (2018). WHO World Mental Health Surveys International College Student Project: Prevalence and distribution of mental disorders. Journal of Abnormal Psychology, 127(7), 623-638. https://doi.org/10.1037/abn0000362

Baer, R. A. (2003). Mindfulness training as a clinical intervention: A conceptual and empirical review. Clinical Psychology: Science and Practice, 10(2), 125-143. https://doi.org/10.1093/clipsy/bpg015 
Baer, R. A., Smith, G. T., Hopkins, J., \& Toney, L. (2006). Using Self-Report Assessment Methods to Explore Facets of Mindfulness. Assessment, 13(1), 27-45. https://doi.org/10.1177/1073191105283504

Baer, R. A., Walsh, E., \& Lykins, E. L. B. (2009). Assessment of mindfulness. In D. Fabrizio (Ed.), Clinical handbook of mind- fulness (pp. 153-168). New York: Springer Science + Business Media.

Bohlmeijer, E., ten Klooster, P. M., Fledderus, M., Veehof, M., \& Baer, R. (2011). Psychometric properties of the five facet mindfulness questionnaire in depressed adults and development of a short form. Assessment, 18(3), 308-320. https://doi.org/10.1177/1073191111408231

Brockman, R., Ciarrochi, J., Parker, P., \& Kashdan, T. (2017). Emotion regulation strategies in daily life: mindfulness, cognitive reappraisal and emotion suppression. Cognitive Behaviour Therapy, 46(2), 91-113. https://doi.org/10.1080/16506073.2016.1218926

Brown, K. W., \& Ryan, R. M. (2003). The benefits of being present: Mindfulness and its role in psychological well-being. Journal of Personality and Social Psychology, 84(4), 822-848. https://doi.org/10.1037/0022-3514.84.4.822

Brown, L., \& Holloway, I. (2008). The adjustment journey of international postgraduate students at an English university: An ethnographic study. Journal of Research in International Education, 7(2), 232-249. https://doi.org/10.1177/1475240908091306

Carlson, J. M., Dikecligil, G. N., Greenberg, T., \& Mujica-Parodi, L. R. (2012). Trait reappraisal is associated with resilience to acute psychological stress. Journal of Research in Personality, 46(5), 609-613. https://doi.org/10.1016/j.jrp.2012.05.003 
Carmody, J., Baer, R. A., Lykins, E. L. B., \& Olendzki, N. (2009). An Empirical Study of the Mechanisms of Mindfulness in a Mindfulness-Based Stress Reduction Program. Journal of Clinical Psychology, 65(6), 613-626. https://doi.org/10.1002/jclp

Cassidy, S. (2015). Resilience building in students: The role of academic self-efficacy. Frontiers in Psychology, 6(NOV), 1-14. https://doi.org/10.3389/fpsyg.2015.01781

Chmitorz, A., Wenzel, M., Stieglitz, R. D., Kunzler, A., Bagusat, C., Helmreich, I., ... Tüscher, 0. (2018). Population-based validation of a German version of the Brief Resilience Scale. PLoS ONE, 13(2), 7-10. https://doi.org/10.1371/journal.pone.0192761

de Bruin, E. I., Topper, M., Muskens, J. G. A. M., Bögels, S. M., \& Kamphuis, J. H. (2012). Psychometric Properties of the Five Facets Mindfulness Questionnaire (FFMQ) in a Meditating and a Non-meditating Sample. Assessment, 19(2), 187-197. https://doi.org/10.1177/1073191112446654

de Vibe, M., Solhaug, I., Tyssen, R., Friborg, O., Rosenvinge, J. H., Sorlie, T., \& Bjorndal, A. (2013). Mindfulness training for stress management: a randomised controlled study of medical and psychology students. BMC Med Educ, 13(1), 107. https://doi.org/10.1186/1472-692013-107

Eftekhari, A., Zoellner, L. A., \& Vigil, S. A. (2009). Patterns of emotion regulation and psychopathology. Anxiety, Stress \& Coping, 22(5), 571-586. https://doi.org/10.1080/10615800802179860

Enebrink, P., Björnsdotter, A., \& Ghaderi, A. (2013). The emotion regulation questionnaire: Psychometric properties and norms for Swedish parents of children aged 10-13 years. Europe's Journal of Psychology, 9(2), 289-303. https://doi.org/10.5964/ejop.v9i2.535 
Erisman, S. M., \& Roemer, L. (2010). A preliminary investigation of the effects of experimentally induced mindfulness on emotional responding to film clips. Emotion, 10(1), 72-82. https://doi.org/10.1037/a0017162

Feldman, G., Hayes, A., Kumar, S., Greeson, J., \& Laurenceau, J. P. (2007). Mindfulness and emotion regulation: The development and initial validation of the Cognitive and Affective Mindfulness Scale-Revised (CAMS-R). Journal of Psychopathology and Behavioral Assessment, 29(3), 177-190. https://doi.org/10.1007/s10862-006-9035-8

Fritz, M. S., \& Mackinnon, D. P. (2015). Required Sample Size to Detect the Mediated Effect, 18(3), 233-239. https://doi.org/10.1111/j.1467-9280.2007.01882.x.Required

Galante, J., Dufour, G., Vainre, M., Wagner, A. P., Stochl, J., Benton, A., ... Jones, P. B. (2018). A mindfulness-based intervention to increase resilience to stress in university students (the Mindful Student Study): a pragmatic randomised controlled trial. The Lancet Public Health, 3(2), e72-e81. https://doi.org/10.1016/S2468-2667(17)30231-1

Garland, E., Gaylord, S., \& Park, J. (2009). The Role of Mindfulness in Positive Reappraisal. Explore: The Journal of Science and Healing, 5(1), 37-44. https://doi.org/10.1016/j.explore.2008.10.001

Garland, E. L., Gaylord, S. A., \& Fredrickson, B. L. (2011). Positive Reappraisal Mediates the Stress-Reductive Effects of Mindfulness: An Upward Spiral Process. Mindfulness, 2(1), 5967. https://doi.org/10.1007/s12671-011-0043-8

Gross, J. J. (1998). The emerging field of emotion regulation: an integrative review. Review of General Psychology, 2(5), 271-299. https://doi.org/10.1017.S0048577201393198

Gross, James J. (2015). Emotion Regulation: Current Status and Future Prospects. Psychological 
Inquiry, 26(1), 1-26. https://doi.org/10.1080/1047840X.2014.940781

Gross, James J., \& John, O. P. (2003). Individual differences in two emotion regulation processes: Implications for affect, relationships, and well-being. Journal of Personality and Social Psychology, 85(2), 348-362. https://doi.org/10.1037/0022-3514.85.2.348

Hayes-Skelton, S., \& Graham, J. (2013). Decentering as a common link among mindfulness, cognitive reappraisal, and social anxiety. Behavioural and Cognitive Psychotherapy, 41(3), 317-328. https://doi.org/10.1017/S1352465812000902

Hayes, A. F. (2018). Introduction to mediation, moderation, and conditional process analysis: $A$ regression-based approach (Second edition). New York: The Guilford Press.

Hayes, A. M., \& Feldman, G. (2004). Clarifying the construct of mindfulness in the context of emotion regulation and the process of change in therapy. Clinical Psychology: Science and Practice. https://doi.org/10.1093/clipsy/bph080

Hindman, R. K., Glass, C. R., Arnkoff, D. B., \& Maron, D. D. (2014). A Comparison of Formal and Informal Mindfulness Programs for Stress Reduction in University Students. Mindfulness, 6,1-12. https://doi.org/10.1007/s12671-014-0331-1

Kay, S. A. (2016). Emotion Regulation and Resilience: Overlooked Connections. Industrial and Organizational Psychology, 9(02), 411-415. https://doi.org/10.1017/iop.2016.31

Keng, S. L., Robins, C. J., Smoski, M. J., Dagenbach, J., \& Leary, M. R. (2013). Reappraisal and mindfulness: A comparison of subjective effects and cognitive costs. Behaviour Research and Therapy, 51(12), 899-904. https://doi.org/10.1016/j.brat.2013.10.006

Lynch, S., Gander, M. L., Kohls, N., Kudielka, B., \& Walach, H. (2011). Mindfulness-based coping with university life: A non-randomized wait-list-controlled pilot evaluation. Stress and 
Health. https://doi.org/10.1002/smi.1382

Monteiro, N. M., Balogun, S. K., \& Oratile, K. N. (2014). Managing stress: The influence of gender, age and emotion regulation on coping among university students in Botswana. International Journal of Adolescence and Youth. Taylor \& Francis. https://doi.org/10.1080/02673843.2014.908784

Montgomery, C., Hatton, N. P., Fisk, J. E., Ogden, R. S., \& Jansari, A. (2010). Assessing the functional significance of ecstasy-related memory deficits using a virtual paradigm, (November 2009), 318-325. https://doi.org/10.1002/hup

Monti, J. D., \& Rudolph, K. D. (2014). Emotional awareness as a pathway linking adult attachment to subsequent depression. Journal of Counseling Psychology, 61(3), 374-382. https://doi.org/10.1037/cou0000016

Oman, D., Shapiro, S. L., Thoresen, C. E., Plante, T. G., \& Flinders, T. (2008). Meditation lowers stress and supports forgiveness among college students: A randomized controlled trial. Journal of American College Health, 56(5), 569-578. https://doi.org/10.3200/JACH.56.5.569-578

Opialla, S., Lutz, J., Scherpiet, S., Hittmeyer, A., Jäncke, L., Rufer, M., ... Brühl, A. B. (2014). Neural circuits of emotion regulation: a comparison of mindfulness-based and cognitive reappraisal strategies. European Archives of Psychiatry and Clinical Neuroscience, 265(1), 45-55. https://doi.org/10.1007/s00406-014-0510-z

Palmer, A. A. A., \& Rodger, S. (2009). Mindfulness, stress, and coping among university students. [References]. Canadian Journal of Counselling, 43(3), 198-212.

Pidgeon, A. M., \& Keye, M. (2014). Relationship between Resilience, Mindfulness, and 
Psychological Well-Being in University Students. International Journal of Liberal Arts and Social Science, 2(5), 27-32.

Pogrebtsova, E., Craig, J., Chris, A., O’Shea, D., \& González-Morales, M. G. (2018). Exploring daily affective changes in university students with a mindful positive reappraisal intervention: A daily diary randomized controlled trial. Stress and Health, 34(1), 46-58. https://doi.org/10.1002/smi.2759

Pooley, J. A., \& Cohen, L. (2010). Resilience: A Definition in Context. The Australian Community Psychologist, 22(1), 30-37.

Prakash, R. S., Whitmoyer, P., Aldao, A., \& Schirda, B. (2015). Mindfulness and emotion regulation in older and young adults. Aging \& Mental Health, 7863(November), 1-11. https://doi.org/10.1080/13607863.2015.1100158

Regehr, C., Glancy, D., \& Pitts, A. (2013). Interventions to reduce stress in university students: A review and meta-analysis. Journal of Affective Disorders, 148(1), 1-11. https://doi.org/10.1016/j.jad.2012.11.026

Rodríguez-Rey, R., Alonso-Tapia, J., \& Hernansaiz-Garrido, H. (2016). Reliability and validity of the Brief Resilience Scale (BRS) Spanish Version. Psychological Assessment, 28(5), e101e110. https://doi.org/10.1037/pas0000191

Rogers, H. B. (2013). Mindfulness Meditation for Increasing Resilience in College Students. Psychiatric Annals, 43(12), 545-548. https://doi.org/10.3928/00485713-20131206-06

Sauer, S., Walach, H., Schmidt, S., Hinterberger, T., Lynch, S., Büssing, A., \& Kohls, N. (2013). Assessment of Mindfulness: Review on State of the Art. Mindfulness, 4(1), 3-17. https://doi.org/10.1007/s12671-012-0122-5 
Schmidt, C., \& Vinet, E. (2016). Mindfulness: Validation of the Five Facet Mindfulness Questionnaire (FFMQ) in Chilean University Students. Terapia Psicológica; Vol. 33, Núm. 2 (2015); 93-102. Retrieved from https://revistaschilenas.uchile.cl/handle/2250/80819

Segal, Z., Williams, J., \& Teasdale, J. (2002). Mindfulness-based cognitive therapy for depression. New York: The Guilford Press.

Shiota, M. N. (2006). Silver linings and candles in the dark: Differences among positive coping strategies in predicting subjective well-being. Emotion, 6(2), 335-339. https://doi.org/10.1037/1528-3542.6.2.335

Smith, B. W., Dalen, J., Wiggins, K., Tooley, E., Christopher, P., \& Bernard, J. (2008). The brief resilience scale: Assessing the ability to bounce back. International Journal of Behavioral Medicine, 15(3), 194-200. https://doi.org/10.1080/10705500802222972

Sugiura, Y., Sato, A., Ito, Y., \& Murakami, H. (2012). Development and Validation of the Japanese Version of the Five Facet Mindfulness Questionnaire. Mindfulness, 3(2), 85-94. https://doi.org/10.1007/s12671-011-0082-1

Sung-Youl, C. (2015). Study on Validity and Reliability of Five Facet Mindfulness Questionnaire ( FFMQ ) for Measuring Mindfulness Meditation Program Before and After. Journal of Oriental Neuropsychiatry, 26(2), 181-190.

Thompson, R. W., Arnkoff, D. B., \& Glass, C. R. (2011). Conceptualizing mindfulness and acceptance as components of psychological resilience to trauma. Trauma, Violence, and Abuse, 12(4), 220-235. https://doi.org/10.1177/1524838011416375

Tran, U. S., Glück, T. M., \& Nader, I. W. (2013). Investigating the Five Facet Mindfulness Questionnaire (FFMQ): Construction of a Short Form and Evidence of a Two-Factor Higher 
Order Structure of Mindfulness. Journal of Clinical Psychology, 69(9), 951-965. https://doi.org/10.1002/jclp.21996

Troy, A. S., \& Mauss, I. B. (2011). Resilience in the face of stress: Emotion regulation as a protective factor. In S. M. Southwick, B. T. Litz, D. Charney, \& M. J. Friedman (Eds.), Resilience and Mental Health: Challenges Across the Lifespan (pp. 30-44). Cambridge: Cambridge University Press. https://doi.org/10.1017/CB09780511994791.004

Van Gordon, W., Shonin, E., Sumich, A., Sundin, E. C., \& Griffiths, M. D. (2014). Meditation Awareness Training (MAT) for Psychological Well-Being in a Sub-Clinical Sample of University Students: A Controlled Pilot Study. Mindfulness, 5(4), 381-391. https://doi.org/10.1007/s12671-012-0191-5

Veehof, M. M., Ten Klooster, P. M., Taal, E., Westerhof, G. J., \& Bohlmeijer, E. T. (2011). Psychometric properties of the Dutch Five Facet Mindfulness Questionnaire (FFMQ) in patients with fibromyalgia. Clinical Rheumatology, 30(8), 1045-1054. https://doi.org/10.1007/s10067-011-1690-9

Vujanovic, A. A., Bonn-Miller, M. O., Bernstein, A., McKee, L. G., \& Zvolensky, M. J. (2010). Incremental validity of mindfulness skills in relation to emotional dysregulation among a young adult community sample. Cognitive Behaviour Therapy, 39(3), 203-213. https://doi.org/10.1080/16506070903441630

Wang, L., Xu, H., Zhang, X., \& Fang, P. (2017). The relationship between emotion regulation strategies and job search behavior among fourth-year university students. Journal of Adolescence, $59(31100757)$, 139-147. https://doi.org/10.1016/j.adolescence.2017.06.004

Watson, P. (2016). Rules of thumb on magnitudes of effect size. MRC Cognition and Brain 
Sciences Unit.

Waxman, H. C., Gray, J. P., \& Padron, Y. N. (2003). Diversity \& Excellence Review of Research on Educational Resilience Review of Research on Educational Resilience. Diversity.

Webster, E. A., \& Hadwin, A. F. (2015). Emotions and emotion regulation in undergraduate studying: examining students' reports from a self-regulated learning perspective. $\begin{array}{lll}\text { Educational } & \text { Psychology, } & \text { 35(7), }\end{array}$ https://doi.org/10.1080/01443410.2014.895292

Wu, W., \& Hammond, M. (2011). Challenges of university adjustment in the UK: A study of East Asian master's degree students. Journal of Further and Higher Education, 35(3), 423-438. https://doi.org/10.1080/0309877X.2011.569016

Young, T. J., Sercombe, P. G., Sachdev, I., Naeb, R., \& Schartner, A. (2013). Success factors for international postgraduate students' adjustment: exploring the roles of intercultural competence, language proficiency, social contact and social support. European Journal of Higher Education, 3(2), 151-171. https://doi.org/10.1080/21568235.2012.743746 


\section{Tables}

Table 1. Demographic characteristics of the sample.

\begin{tabular}{|c|c|c|}
\hline & $\mathrm{N}(\%)$ & $M$ (SD) Range \\
\hline Age & & $28.57(9.97) 19-70$ \\
\hline \multicolumn{3}{|l|}{ Gender } \\
\hline Female & $675(83.2)$ & \\
\hline Male & $136(16.8)$ & \\
\hline \multicolumn{3}{|l|}{ Degree } \\
\hline Undergraduate (BSc, BA) & $437(53.9)$ & \\
\hline Taught postgraduate (MSc, MA) & $181(22.3)$ & \\
\hline Research postgraduate (MRes, MPhil) & $15(1.8)$ & \\
\hline Research doctoral (PhD) & $160(19.7)$ & \\
\hline Professional doctoral (EngD, JD) & $18(2.2)$ & \\
\hline \multicolumn{3}{|l|}{ Subject } \\
\hline Arts and Humanities & $56(17.8)$ & \\
\hline Engineering and Technology & $232(6.9)$ & \\
\hline Life Sciences and Medicine & $68(28.6)$ & \\
\hline Natural Sciences & $311(8.4)$ & \\
\hline Social Sciences and Management & $144(38.3)$ & \\
\hline Total & $811(100)$ & \\
\hline
\end{tabular}


Table 2. Descriptive data for the adopted scales.

\begin{tabular}{lccc}
\hline & $M$ (Tot) & SD & Q \\
\hline ERQ-CR & $28.09(42)$ & 7.53 & .805 \\
BRS & $18.59(30)$ & 5.48 & .893 \\
FFMQ & $122.3(140)$ & 22.31 & .762 \\
\hline
\end{tabular}

Note. $\alpha=$ Cronbach's alpha; BRS = Brief Resilience Scale; $M$ (Tot) = mean score (total score); ERQ-CR = Emotion Regulation Questionnaire - Cognitive Reappraisal score; FFMQ = Five Facets of Mindfulness Questionnaire - Total score; SD = standard deviation.

Table 3: Results of correlational analysis.

\begin{tabular}{lccc}
\hline & ERQ-CR & BRS & FFMQ \\
\hline ERQ-CR & 1 & & \\
BRS & $.448^{* *}$ & 1 & 1 \\
FFMQ & $.505^{* *}$ & $.612^{* *}$ & \\
\hline
\end{tabular}

Note. $^{* *}=p<.001 ; \mathrm{BRS}=$ Brief Resilience Scale; ERQ-CR = Emotion Regulation Questionnaire - Cognitive Reappraisal score; FFMQ = Five Facets of Mindfulness Questionnaire - Total score 


\section{Figures}

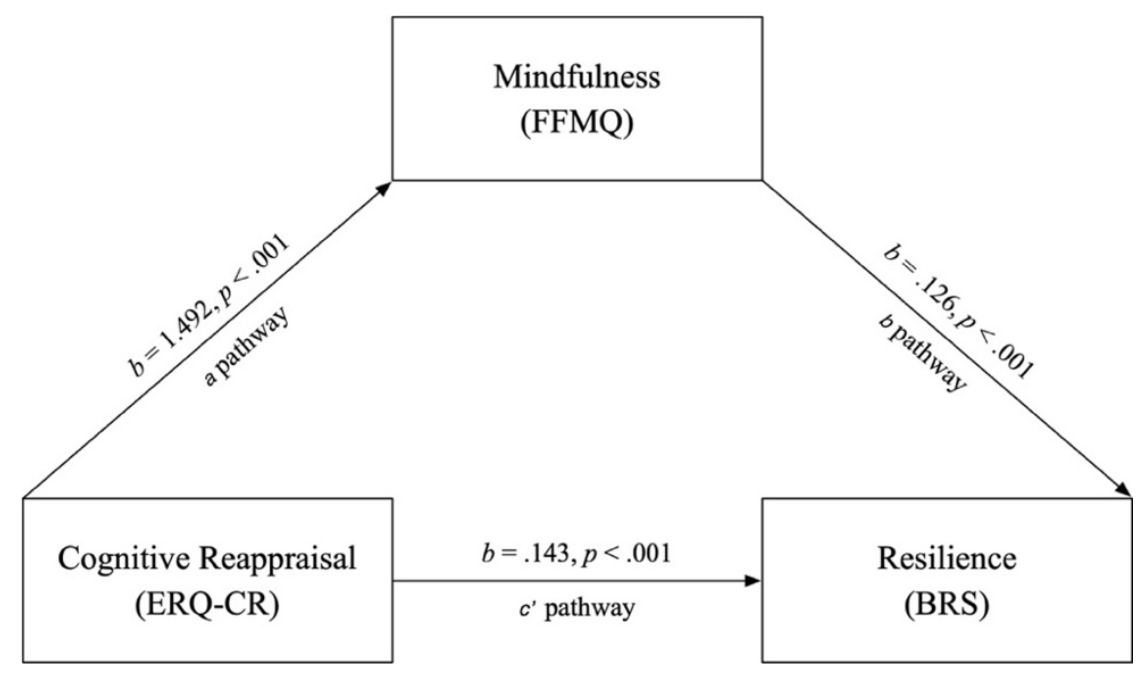

Figure 1. Path diagram of mediation model based on the whole sample. 